\title{
The Annual Cycle of Circulation of the Southwest Subtropical Pacific, Analyzed in an Ocean GCM*
}

\author{
WILLIAM S. KESSLER \\ NOAA/Pacific Marine Environmental Laboratory, Seattle, Washington \\ LIONEL GOURDEAU \\ Institut de Recherche pour le Développement, Nouméa, New Caledonia
}

(Manuscript received 11 April 2006, in final form 2 August 2006)

\begin{abstract}
An ocean GCM, interpreted in light of linear models and sparse observations, is used to diagnose the dynamics of the annual cycle of circulation in the western boundary current system of the southwest Pacific Ocean. The simple structure of annual wind stress curl over the South Pacific produces a large region of uniformly phased, stationary thermocline depth anomalies such that the western subtropical gyre spins up and down during the year, directing flow anomalies alternately toward and away from the boundary at its northern end, near $10^{\circ} \mathrm{S}$. The response of the western boundary currents is to redistribute these anomalies northward toward the equator and southward to the subtropical gyre, a redistribution that is determined principally by linear Rossby processes, not boundary dynamics. When the subtropical gyre and South Equatorial Current (SEC) are strong (in the second half of the year), the result is both increased equatorward transport of the New Guinea Coastal Current and poleward transport anomalies along the entire Australian coast. Because of this opposite phasing of boundary current anomalies across $10^{\circ} \mathrm{S}$, annual migration of the bifurcation point of the total SEC, near $18^{\circ} \mathrm{S}$ in the mean, has no significance regarding variability of transport from subtropics to equator.
\end{abstract}

\section{Introduction}

Attention has focused on circulation in the southwestern Pacific Ocean because of its position athwart a major pathway from the subtropics to the equator. These pathways are of great interest because changes in either the temperature or amount of water arriving at the equator have the potential to modulate the ENSO cycle and thereby produce basin-scale climate feedbacks (Gu and Philander 1997; Kleeman et al. 1999; Schneider et al. 1999; Giese et al. 2002; Galanti and Tziperman 2003; Luo et al. 2003; Schneider 2004). Both observational (Tsuchiya 1981; Tsuchiya et al. 1989) and

* Pacific Marine Environmental Laboratory Contribution Number 2921.

Corresponding author address: William S. Kessler, NOAA/ Pacific Marine Environmental Laboratory, 7600 Sand Point Way NE, Seattle, WA 98115.

E-mail: william.s.kessler@noaa.gov

DOI: $10.1175 / \mathrm{JPO} 3046.1$

(C) 2007 American Meteorological Society model tracer studies (Blanke and Raynaud 1997; Izumo et al. 2002; Fukumori et al. 2004; Goodman et al. 2005) suggest that a substantial fraction of the water arriving at the equatorial cold tongue has passed through the western boundary current system of the South Pacific. Thus the overriding physical oceanographic issue in the southwest Pacific is how inflow from the subtropical gyre is redistributed meridionally as it arrives at the western boundary.

Despite its apparent importance to the climate system, few observations are available to diagnose the processes of transport through the complicated geography of the southwest Pacific (Fig. 1a). The region is remote and difficult to work in, and its large time variability and strong narrow currents in a very complex bathymetry pose serious challenges to an observing strategy. The pioneering Western Equatorial Pacific Ocean Climate Studies (WEPOCS) cruises of 1985-86 (Lindstrom et al. 1987) provided important snapshots of the tropical end of this system, but observations in the Coral Sea consist of scattered surveys that only sketch the large-scale mean flows. 


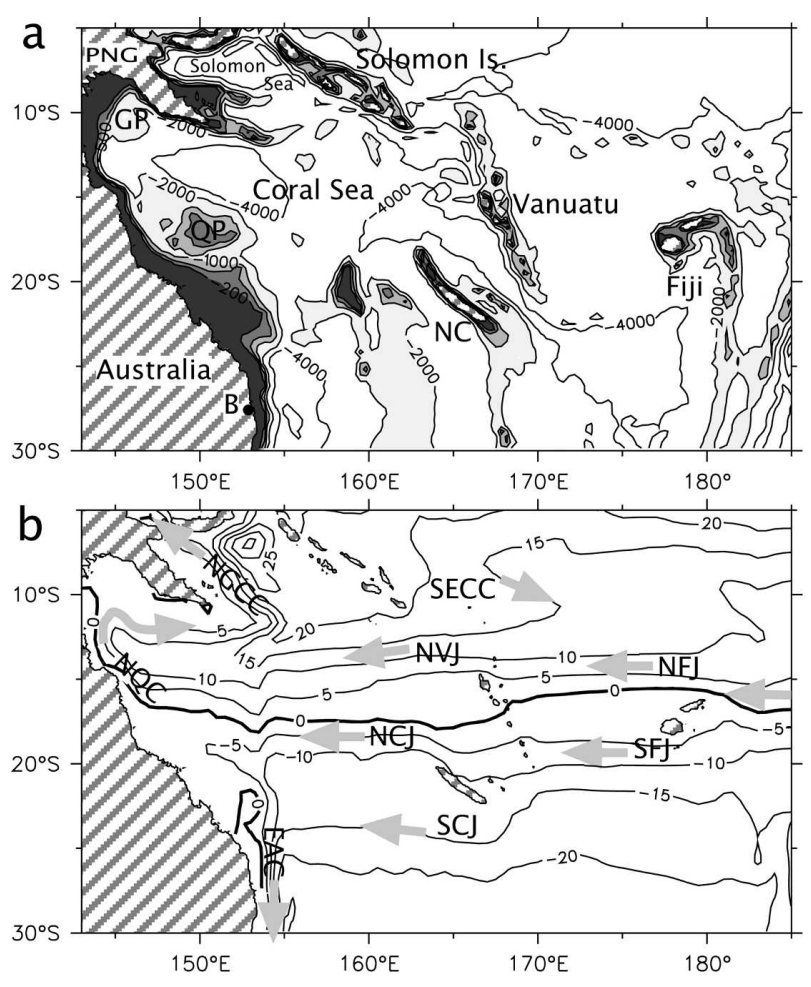

FIG. 1. (a) Bathymetry of the southwest Pacific. Gray shading at 200-, 500-, 1000-, and 2000-m depths; contours for 4000- and 6000-m depths. Hatching shows land. Island groups and seas are labeled (PNG indicates Papua New Guinea and NC indicates New Caledonia). QP marks the 300-m-deep Queensland Plateau, GP the Gulf of Papua, and B the city of Brisbane, Australia. (b) Streamfunction of OGCM transport, with contours every $5 \mathrm{~Sv}$. Its value at the coast of Australia is chosen to be zero. Named currents are listed in section 3 .

Investigation of the subtropical part of this circulation is motivated by the fact that the bifurcation of the South Equatorial Current (SEC), roughly at $18^{\circ} \mathrm{S}$ along the coast of Australia, separates water that flows into the equatorial current system from that which recirculates in the subtropical gyre (Fig. 1b; Godfrey 1989; Qu and Lindstrom 2002; Blanke et al. 2001). Thus, it has been thought that migration of the bifurcation point could be a key variable in the modulation of equatorial climate. For instance, if the winds changed such that the bifurcation moved north, that might be seen as an indication of smaller transport toward the equator. Similar suggestions have been made regarding the bifurcation of the North Equatorial Current (NEC) at the Philippine coast (Qiu and Lukas 1996; Qu and Lukas 2003; Kim et al. 2004). However, we argue below that, at least for annual variability in the South Pacific, shifts of the bifurcation latitude do not signify corresponding anomalies of transport to the equator; indeed, those can be systematically of the opposite sign to what would be deduced from migration of the bifurcation.
Awaiting observations sufficient to diagnose the circulation, the present paper examines this system in an ocean general circulation model, checked where possible with available observations. While it is likely that interannual and interdecadal variability will be of primary climatic interest, here we take a first step by looking at the annual cycle. Given the present state of ignorance of the mechanisms controlling partition of flow at the western boundary, it seems worthwhile to examine these processes in the simplest possible context, for which we can take advantage of the ability to produce annual averages over more than a decade during which the wind forcing is sampled by satellite scatterometry.

\section{Model and data}

\section{a. ORCA OGCM}

\section{1) Model formulation}

The model used in this study is a global ocean configuration of the free-surface Océan Parallélisé (OPA) ocean general circulation model, known as ORCA (Madec et al. 1998). The horizontal resolution is a 0.5 degree Mercator mesh, with 31 prescribed $z$ levels from the surface to $5500 \mathrm{~m}$, and $10-\mathrm{m}$ vertical resolution in the upper $120 \mathrm{~m}$. Atmospheric boundary conditions are surface fluxes of momentum, heat, and freshwater. Wind and precipitation are prescribed; other fluxes (heat and evaporation) are diagnosed from specified atmospheric variables through bulk formulas. The model was initialized with Levitus et al. (1998) temperature and salinity, and spun up from rest for $10 \mathrm{yr}$ with an average annual cycle of the same forcing used in the full run.

Output fields studied here are for the 1992-2002 period, forced by European Remote Sensing Satellites 1 and 2 (ERS-1-2) wind stress for 1992-2000 and the SeaWinds satellite scatterometer (known as QuikSCAT) for the final two years (Schlax et al. 2001), and by the Climate Prediction Center (CPC) Merged Analysis of Precipitation (CMAP) precipitation flux (Xie and Arkin 1997). The heat and evaporation fluxes are diagnosed from National Centers for Environmental Prediction-National Center for Atmospheric Research (NCEP-NCAR) reanalysis (Kalnay et al. 1996) air temperature. Output used for the present paper was sampled every 5 days and was used to produce a monthly average annual cycle.

\section{2) ESTIMATION OF WESTERN BOUNDARY TRANSPORT}

In common with other western boundary current systems, the East Australian Current produces a signifi- 
cant recirculation, with a sequence of prominent eddies, that complicates the estimation of its transport (Mata et al. 2000; Ridgway and Dunn 2003; Bowen et al. 2005). Although much of the recirculation occurs south of the $30^{\circ} \mathrm{S}$ cutoff of the present study (Ridgway and Dunn 2003), we avoid possible confusion by estimating the transport as an integral extending offshore to encompass the entire region influenced by western boundary dynamics. Here, we tried and compared several types of estimates of western boundary transport, including selecting by hand the model grid points that make up the boundary current, level by level. We found that all of these measures gave very similar results, both for the mean and the annual variations, and finally chose to simply integrate meridional velocity from the coast out to $160^{\circ} \mathrm{E}$ south of $20^{\circ} \mathrm{S}$, and to $156^{\circ} \mathrm{E}$ farther north. The reason for this lack of sensitivity is that meridional velocity in the entire region between the coast and our cutoff longitudes is so dominated by western boundary flows, both in the mean (Fig. 1b) and the variability (see section $4 \mathrm{~b}$ ), that even a crude criterion suffices for this purpose.

A similar technique to estimate the western boundary transport at the tropical end of this system might be considered. We have not done so here, and in fact have restricted attention to the region south of the straits that carry western boundary flow to the equator through the north end of the Solomon Sea (Vitiaz and Solomon Straits, and St. Georges Channel), for two reasons. First, the relative distribution of flow among these straits has important consequences downstream on the equator (e.g., Tsuchiya et al. 1989), so it could be misleading to group together the different tropical western boundary constituents. Second, the relatively coarse grid and bathymetry of the global model used here is insufficient to accurately represent these narrow straits (e.g., the modeled Vitiaz Strait is only about twothirds the actual depth, and St. Georges Channel is absent). Experiments adjusting the shape and depth of the straits in the model produced very large changes in distribution of flow among them (though not their total northward transport) that could not be validated based on existing observations. We regard this uncertainty as a research problem that has not yet been solved, either observationally or in its model representation, and therefore avoid it here by analyzing the model output only as far north as the central Solomon Sea.

\section{b. CARS data}

The Commonwealth Scientific and Industrial Research Organisation (CSIRO) Atlas of Regional Seas (CARS) compilation was produced by Ridgway et al. (2002) from more than 65000 temperature and salinity profiles in the region $10^{\circ} \mathrm{N}-50^{\circ} \mathrm{S}, 100^{\circ} \mathrm{E}-180^{\circ}$ using a locally weighted least squares mapping. The compilation uses a topographic weighting to minimize contamination of deeper oceanic regions by continental shelf waters, with an additional weighting function to avoid interpolation across topographic barriers. CARS fields are produced on a $1 / 2^{\circ}$ latitude-longitude grid with 56 vertical levels. A full-depth mean and first and second annual harmonic components (to $1000 \mathrm{~m}$ ) are provided, though in our calculations it appeared that in some regions the harmonics were suspect; this is not surprising in view of the sparse sampling available. Ridgway and Dunn (2003) studied the CARS data to describe the mean circulation of the southwest Pacific, focusing on the East Australian Current system. Here we use CARS to find mean (and in a few cases annual cycle) geostrophic currents for comparison with the OGCM fields.

\section{Mean circulation}

Although this paper focuses on the annual cycle, we briefly describe the regional mean circulation in the model as background and to allow comparison with observed structures, for which only a reliable mean is available at most locations.

Inflow to the Coral Sea comes principally through the gap between the northern tip of the New Caledonian reef system (near $\left.19^{\circ} \mathrm{S}, 164^{\circ} \mathrm{E}\right)$ and the southernmost of the Solomon Islands $\left(11^{\circ} \mathrm{S}, 161^{\circ} \mathrm{E}\right)$ (Fig. 1b), with an additional inflow south of New Caledonia (Fig. 2). The term South Equatorial Current (SEC) is used to describe the entire westward limb of the southern subtropical gyre, extending from at least $30^{\circ} \mathrm{S}$ to $4^{\circ} \mathrm{N}$, but the current is broken up into a series of jets that are particularly prominent west of the large islands of the western Pacific (Ridgway and Dunn 2003). Although this is principally due to the effects of island blocking (Webb 2000), Kessler and Gourdeau (2006) showed that some of the filamentary structure is inherent in the wind forcing and occurs well east of the islands. Prominent jets in the western Pacific are marked in Fig. 1b, due to blocking by Fiji [North and South Fiji Jets (NFJ and SFJ); Stanton et al. 2001], by New Caledonia [North and South Caledonian Jets (NCJ and SCJ)], and by Vanuatu [North Vanuatu Jet (NVJ)].

A meridional section of zonal current just west of New Caledonia up to the southern tip of the Solomon Islands (Fig. 2) shows the vertical structure of the SCJ, NCJ, and NVJ, from the observed CARS climatology and the OGCM. The three jets are the dominant feature of the SEC at this longitude, and persist westward across the Coral Sea (Fig. 1b). The shallow eastward 


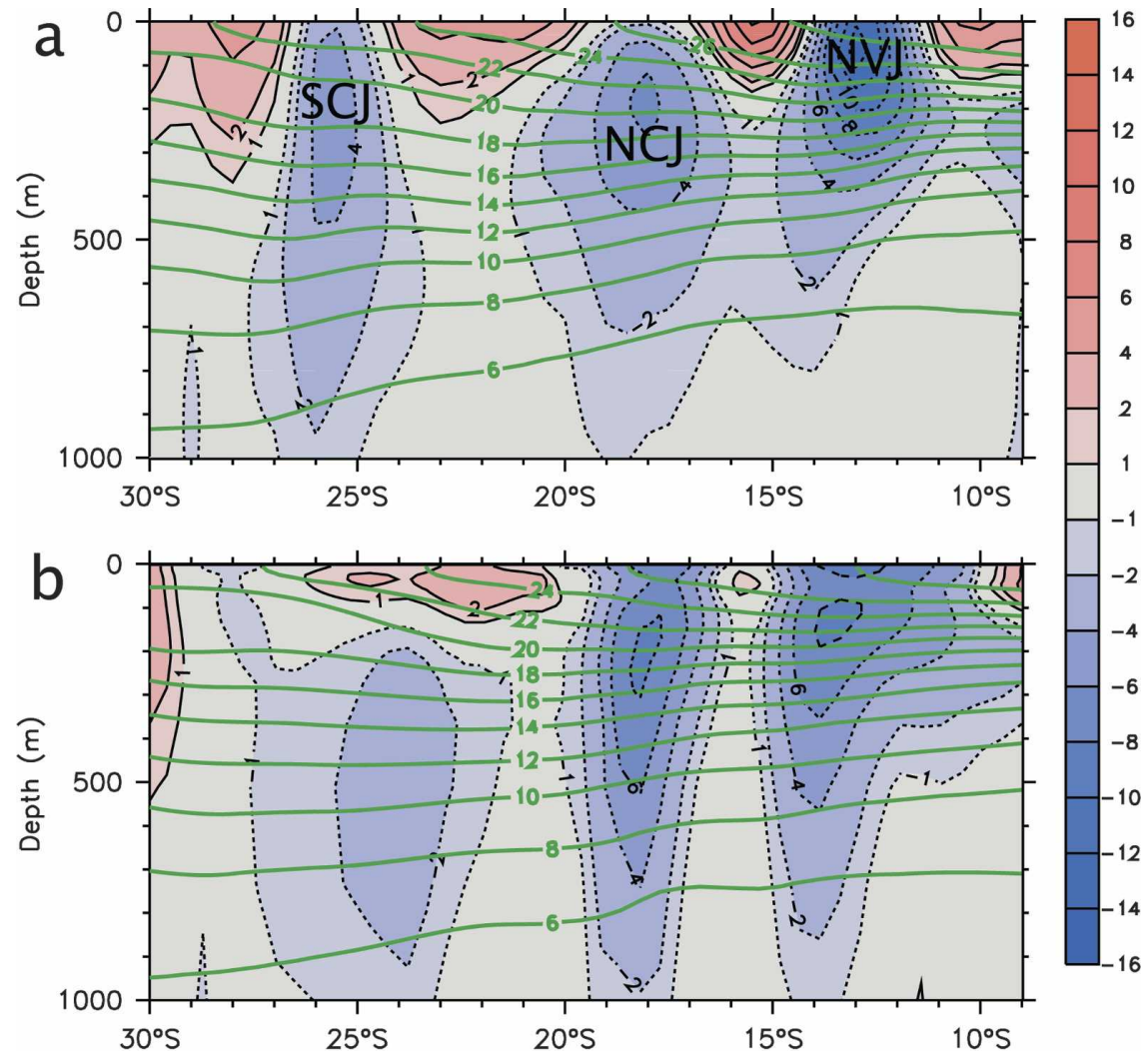

FIG. 2. Mean zonal current along $162^{\circ}-165^{\circ} \mathrm{E}$ (just west of New Caledonia; $\mathrm{m} \mathrm{s}^{-1}$ ) from (a) the CARS climatology ( $u_{g}$ relative to $2000 \mathrm{~m}$ ) and (b) from the OGCM (total $u$ ). Blue color (dashed contours) indicates westward flow and red color (line contours) eastward. Overlay (green) contours show isotherms. Labels in (a) indicate the South and North Caledonia Jets and the North Vanuatu Jet (see Fig. 1).

flow at $9^{\circ}-10^{\circ} \mathrm{S}$ is the South Equatorial Countercurrent (SECC; Delcroix et al. 1992; Gouriou and Toole 1993; Chen and Qiu 2004), which is weak in the mean but strengthens in austral summer. Farther south, the tendency toward eastward or weaker westward flow at the surface is the Subtropical Countercurrent, due to peeling off of isotherms above the main thermocline, and consequent shallow eastward shear (Reid 1986; deSzoeke 1987; Huang and Qiu 1998; Qu and Lindstrom 2002). This reflects the general tilt of the subtropical gyre, with the deepest point of $20^{\circ} \mathrm{C}$ near $14^{\circ} \mathrm{S}$, of $15^{\circ} \mathrm{C}$ near $22^{\circ} \mathrm{S}$, of $10^{\circ} \mathrm{C}$ near $27^{\circ} \mathrm{S}$, and of $5^{\circ} \mathrm{C}$ near $32^{\circ} \mathrm{S}$ at 1100-m depth (Fig. 2; see Roemmich and Cornuelle 1990). Above these centers of the gyre bowl, eastward shear due to upward-sloping isotherms weakens or reverses the westward SEC. This change in isotherm slope gives rise to baroclinic instability and consequent high eddy energy (Qiu and Chen 2004). In the vertical integral, the gyre center (zero zonal transport line) is near $30^{\circ} \mathrm{S}$, the southern edge of the region under consideration here, but the tilt means that some of the eastward limb of the gyre occurs as shallow flows north of $30^{\circ} \mathrm{S}$, as seen in Fig. 2. The thermocline and currents in the model agree well with observations across the section. In the model, the mean SCJ transports about 12 $\mathrm{Sv}\left(1 \mathrm{~Sv} \equiv 10^{6} \mathrm{~m}^{3} \mathrm{~s}^{-1}\right)$, the NCJ about $11 \mathrm{~Sv}$, and the NVJ about $18 \mathrm{~Sv}$. Two previous analyses of comparable sections were by Scully-Power (1973), who estimated a transport of $29.7 \mathrm{~Sv}$ including the NCJ and NVJ, and by Andrews and Clegg (1989), who estimated $20 \mathrm{~Sv}$ of transport of the NVJ. Both of these estimates are similar to the present model results.

The only existing full-depth meridional section across the Coral and Tasman Seas was the World Ocean Circulation Experiment (WOCE) P11S line from the tip of New Guinea, south along $154^{\circ}-156^{\circ} \mathrm{E}$ (i.e., much farther west than the section shown in Fig. 2) during JuneJuly 1993 (Sokolov and Rintoul 2000). Taking geostrophic velocities relative to the bottom, they estimated the westward transport of the SEC across this section between New Guinea and about $20^{\circ} \mathrm{S}$ to be 55 Sv. This is about $50 \%$ larger than corresponding mean 
transports in either the model or the CARS climatology (relative to $2000 \mathrm{~m}$ ). Repeating the Sokolov and Rintoul calculation with P11S data taken relative to $2000 \mathrm{~m}$ gives a transport of about $48 \mathrm{~Sv}$, still much larger than climatology. Nor is the discrepancy likely to be seasonal, as annual cycle transport variations (discussed in section $4 \mathrm{~b}$ below) suggest that the far western SEC is seasonally weak in June-July when the P11S section was made. Apparently, the Sokolov and Rintoul P11S section sampled a period of anomalously strong SEC transport; the timing appears right for this to have been a lagged response to the El Niño of 1991/92 (Alory and Delcroix 2002).

SEC inflow from the east feeds nearly equal transport southward in the East Australian Current (EAC), and northward into the Solomon Sea, via the North Queensland Current (NQC) up to the Gulf of Papua, and then the New Guinea Coastal Current (NGCC) (Fig. 1b). This basic structure of the Coral Sea circulation has been known since the early cruises of Wyrtki (1962) and Scully-Power (1973). In the vertical integral the modeled bifurcation is at $17.5^{\circ} \mathrm{S}$, in accord with wind-driven Sverdrup transport estimated using the Godfrey (1989) Island Rule, which shifts the bifurcation latitude slightly south of the zonally integrated zero wind stress curl line. However, corresponding to the gyre tilt, the bifurcation is tilted, with the partition at about $15^{\circ} \mathrm{S}$ at the surface but at $22^{\circ} \mathrm{S}$ by $1000-\mathrm{m}$ depth ( $\mathrm{Qu}$ and Lindstrom 2002). Within this range of latitudes, the southward surface current grows to become the EAC, while the deeper northward current begins the NQC, which appears at the surface north of $15^{\circ} \mathrm{S}$. A coincidence that greatly complicates analysis of the bifurcation is that the Queensland Plateau rises above $300 \mathrm{~m}$ over $15.5^{\circ}-18^{\circ} \mathrm{S}$, with a 1000 -m-deep channel inshore (Fig. 1a). This permits a double western boundary current system in a very complex circulation. Above $300 \mathrm{~m}$, the SEC continues west over the top of the plateau and feeds the southward near-surface EAC against the coast. Below $300 \mathrm{~m}$, the bifurcation shifts quickly to $20^{\circ} \mathrm{S}$, south of the plateau, and the deeper western boundary current is northward, occurring both in the inner channel, where it is known as the Great Barrier Reef Undercurrent (GBRUC; Church 1987; Church and Boland 1983), while a second northward branch flows against the outer slope of the plateau. This vertical structure is averaged over in the model streamfunction (Fig. 1b), but variability of the two filaments will be seen in the annual cycle discussed below.

Since 1991, quarterly eddy-resolving expendable bathythermograph (XBT) transects defining a box around the Tasman Sea have been maintained on volunteer observing ships (Roemmich and Cornuelle 1990;
Morris et al. 1996). The PX30 line from Brisbane Australia to Fiji, passing south of New Caledonia and crossing the EAC near $27^{\circ} \mathrm{S}$ (Fig. 1a), is suitable for comparison with the OGCM, which was forced during nearly the same time period as the XBT observations. The PX30 observations show mean southward EAC transport of $14 \mathrm{~Sv}$ of water warmer than $12^{\circ} \mathrm{C}$ (about 450-m depth; relative to an 800-m reference level), of which about $5 \mathrm{~Sv}$ balances a tight recirculation just offshore (Roemmich et al. 2005). Corresponding warmwater EAC transport in the OGCM, sampled along the same track, is $10 \mathrm{~Sv}$; the difference is consistent with the much weaker model recirculation, about $1 \mathrm{~Sv}$ (note that this is only barely visible in Fig. 1b). While the dominance of Sverdrup dynamics in the long-term average makes it reasonable that model and observations both display the same total boundary layer transport, it is not known why the model produces such a weak recirculation.

Considering the entire Fiji-Brisbane section (with positive transport taken northward and westward across the section), the observations show a net transport of $-3.8 \mathrm{~Sv}$ above $12^{\circ} \mathrm{C}$, which incorporates both westward SFJ/SCJ transport into the Coral Sea and slightly stronger southward EAC outflow out of it (Fig. $1 \mathrm{~b}$ ); the corresponding model value is $-5.3 \mathrm{~Sv}$. While the XBT observations are limited to the upper water, the model additionally shows the top-to-bottom total. Model top-to-bottom EAC transport is $-21 \mathrm{~Sv}$, about twice that above $12^{\circ} \mathrm{C}$; however, total Fiji-Brisbane transport in the OGCM is $-5.4 \mathrm{~Sv}$, almost identical to that in the warm layer alone; in other words, the total transport across this track below $12^{\circ} \mathrm{C}$ is near zero. Thus the model suggests that the deeper part of the EAC is fed from south of Fiji (therefore crossing and recrossing the Fiji-Brisbane XBT line), while a net of about $5 \mathrm{~Sv}$ feeds the shallow EAC from north of Fiji (note that when the streamfunction is chosen to be zero at the coast of Australia as in Fig. 1b, its -5-Sv contour passes just south of Fiji). The increasingly northern source of the near-surface EAC is consistent with the tilt of the subtropical gyre and bifurcation described above.

\section{The annual cycle}

\section{a. Method of representing the annual cycle of transport}

Inspection of sequential maps or movies of annual transport variability makes clear that a coherent, translating signal with a well-defined lag extends from the eastern Tropics to New Guinea, and then south along the axis of the eastern Australian western boundary 
current system. Representing this variability is not straightforward because zonal and meridional velocity components are intertwined along the apparent path of this signal. To accomplish this representation, we first extract the dominant annual signal, and also join the velocity components, using variance ellipses. [The major and minor axes of a variance ellipse are the standard deviations of the perpendicular velocity components after the ellipse has been rotated to express the maximum possible variance in the direction of the major axis (see Preisendorfer 1988).] Annual cycle variance ellipses show the well-organized tropical and alongshore nature of the large-amplitude variance (Fig. 3a). The signal we extract for further analysis is the time series of velocity along the major axes of the ellipses. By definition this represents at least $50 \%$ of the total annual variance at each point; for the large-amplitude signals we will be studying, the fraction is generally $80 \%-90 \%$ or more (note the elongation of most of the ellipses in Fig. 3a). The advantage of this rotation is that it defines a velocity in a spatially varying coordinate system that encompasses both zonal and meridional components in a single quantity, according to the direction of maximum variance. Note, however, that there is a $180^{\circ}$ ambiguity, which can be chosen in either direction along the major axis.

The second step is to decompose the major axis velocity component into its 1 cycle $\mathrm{yr}^{-1}$ ( 1 cpy) harmonic, yielding an amplitude and phase at each point. These, along with the ellipse major axis direction, are used here to define the annual signal of interest. All three of these numbers are combined in Fig. 3b, in which the direction of the vector shows the major axis orientation (not the direction of the mean current), the area of the vector shows the magnitude of the harmonic (scale vector at lower left), and the color shows the phase (month of maximum transport anomaly in the direction of the vector; color scale at right). To emphasize the continuity of the lag from the Tropics and down the coast, the $180^{\circ}$ directional ambiguity of the major axes noted above has been resolved by subjectively choosing for continuity of flow, especially around the corner inside the Gulf of Papua (Fig. 1a). (At each point, the opposite choice of direction could have been made, reversing the vector and shifting the phase by 6 months.) The interpretation of a particular vector, say the large light purple one at $14^{\circ} \mathrm{S}, 145^{\circ} \mathrm{E}$ in Fig. $3 \mathrm{~b}$, is that the annual transport anomaly there is southeastward with largest magnitude during December. Taken as a whole, this representation extracts the signal seen in sequential maps: a lag-coherent fluctuation that begins in the eastern Tropics and progresses southward and westward, and then southward along the western boundary, with about a 6-month lag from $8^{\circ} \mathrm{S}, 165^{\circ} \mathrm{E}$ to $30^{\circ} \mathrm{S}$ along the coast of Australia. Climatological transport anomalies are westward in the interior and southward along the coast during the second half of the year (as indicated by the choice of vector direction in Fig. 3b). Note that virtually all the vectors in Fig. 3b show anomalies appropriate to the second half of the year; a picture of anomalies in the first half would be given by a reversal of all vectors with a 6-month advance of the phases. North of $11^{\circ} \mathrm{S}$, the strong SEC in August-October feeds equatorward transport anomalies along the coasts of New Guinea and the Solomon Islands, with a short time lag due to the rapid propagation of tropical Rossby waves.

\section{b. Annual transport variability}

Annual transport variability in the southwest Pacific is dominated by the Tropics and the western boundary flows (Fig. 3a). The orientation of the variance ellipses is principally zonal in the tropical interior, reflecting a seasonally varying inflow to the western boundary region, and aligned with boundaries near the coasts, indicating changes of strength of the western boundary currents. The two distinct maxima of transport variability offshore of the Australian coast at $14^{\circ}-18^{\circ} \mathrm{S}$ reflect blocking below $300 \mathrm{~m}$ by the Queensland Plateau, which produces a secondary subsurface boundary filament on its outer slope (section 3).

Annual variations of inflow to the Coral Sea region occur primarily north of about $13^{\circ} \mathrm{S}$, with very little transport variability over the central part of the subtropical gyre. Maximum westward flow is in July to October, with earlier anomalies closer to the equator (Fig. 3b). The strongly oscillating signal east of the Solomon Islands includes the shallow SECC, which has its eastward maximum in January to March (Chen and Qiu 2004), consistent with Fig. 3b, which shows peak westward anomalies in August in this region. In our representation of annual, vertically integrated anomalies, SECC variability does not appear as a discrete current, but is simply part of a larger-scale oscillation during the course of the year (Fig. 3b); where the mean is weak (Fig. 1b), the flow reverses direction during the climatological year.

Much of the annual SEC inflow signal is balanced by flow toward the equator in two branches: one along the coast of New Guinea (the NGCC), and a previously undescribed flow along the east coast of the Solomon Islands (Fig. 3b); both are anomalously equatorward in August-October. Thus the location of the "western boundary" of the South Pacific in this latitude range seems ambiguous; perhaps comparable to the situation around the Queensland Plateau. [However, this only 

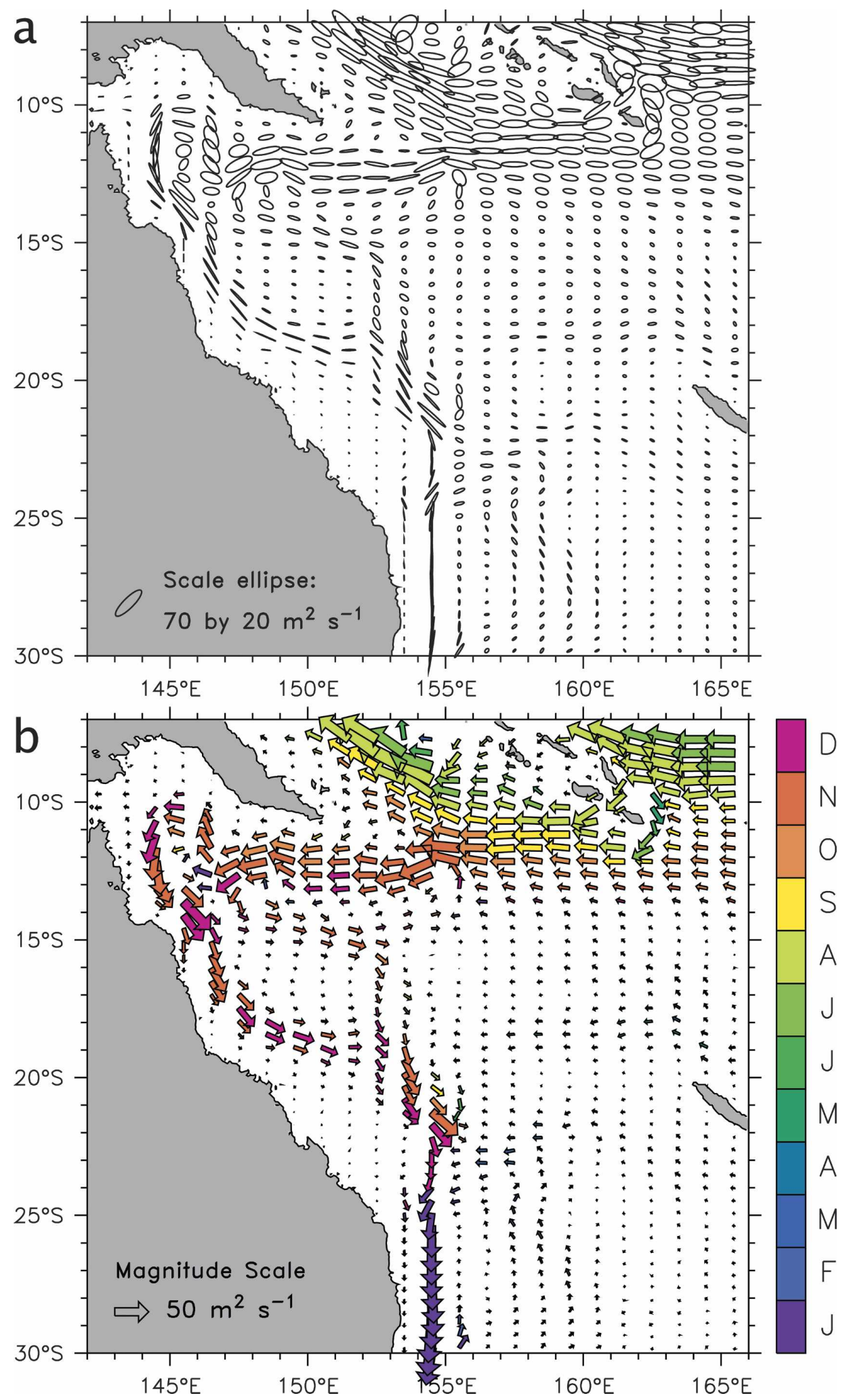

FIG. 3. The annual cycle of 0-2060-m transport anomalies in the OGCM (see section 4a). (a) Annual cycle variance ellipses (scale at lower left). (b) Annual cycle transport anomalies. The area of each vector indicates the magnitude of the 1-cpy harmonic (scale at lower left), the direction points along the major axes of the variance ellipses, and the color indicates the month of maximum transport in the direction of the vector (scale at right). The choice of vector direction is arbitrary: each vector could be reversed, and its phase advanced by 6 months, to show the opposite phase of annual anomalies. The scales in (a) and (b) are consistent because a $50 \mathrm{~m}^{2} \mathrm{~s}^{-1}$ harmonic amplitude as in (b) produces an RMS larger by a factor of $2^{1 / 2}$, or about $70 \mathrm{~m}^{2} \mathrm{~s}^{-1}$ as in (a). 
applies to annual variability; unlike the Queensland Plateau, the mean western boundary current at $10^{\circ}$ to $6^{\circ} \mathrm{S}$ in the model occurs entirely against the coast of New Guinea (Fig. 1b).] Without in situ observations to verify the model representation of this transport, an annual cycle of geostrophic surface velocity was estimated from TOPEX/Jason altimetric sea surface heights (Fu et al. 1994), and a diagnosis analogous to Fig. 3 was constructed (not shown). This largely agreed in pattern and phase with the integrated transport shown in Fig. 3, except that there was no sign of oscillating equatorward flow against the east coast of the Solomons. Examination of the vertical structure of the OGCM currents shown in Fig. 3b confirmed that its shallow flows were consistent with the altimetrically derived surface currents: the equatorward flow seen in Fig. 3 occurs below the surface layer, and especially below the thermocline to about $1200 \mathrm{~m}$. Thus, the model annually generates a double western boundary system at depth, the dynamics of which remain unknown, though the realism of this feature cannot be currently checked.

South of New Guinea, the entire Australian boundary current system fluctuates coherently, with a lag of about 2 months from north to south, including both the southward EAC and the northward NQC (Fig. 3b). As a consequence of this general poleward anomaly in November-January, the northward NQC weakens while the southward EAC strengthens. These changes are largely coherent over the water column, with little phase variation in the upper $1000 \mathrm{~m}$; below that, deep currents lead the surface layer by 1-2 months. Top-tobottom amplitude of western boundary current anomalies is about $\pm 8 \mathrm{~Sv}$ at $12^{\circ} \mathrm{S}$, decreasing to about $\pm 4 \mathrm{~Sv}$ by $30^{\circ} \mathrm{S}$, which is about one-third of the mean transport of the NQC and about one-fifth of the mean transport of the EAC in the OGCM.

Two observational papers provide the opportunity to evaluate the model depiction of the boundary currents. Ridgway and Godfrey (1997) estimated the annual amplitude of EAC transport south of $24^{\circ} \mathrm{S}$ based on measured near-coastal integrated pressure and the assumption that the seasonal cycle of pressure far offshore was negligible. This is analogous to our integration of boundary current transport across the entire EAC, including the recirculation [section $2 \mathrm{a}(2)$ ]. (Consistent with the OGCM and Rossby model results discussed in section 4c below, showing large annual thermocline depth variability in the interior, they commented that such an assumption was "not even qualitatively useful" north of $24^{\circ} \mathrm{S}$.) Their method gave estimated annual transport amplitudes of $5-6 \mathrm{~Sv}$ over $24^{\circ}-28^{\circ} \mathrm{S}$, with maximum southward flow in November-February. This is in phase with but about $40 \%$ larger than the OGCM annual cycle.

The Brisbane-Fiji high-resolution XBT line of Roemmich et al. (2005) resolves the annual cycle of transport above the $12^{\circ} \mathrm{C}$ isotherm and gives an amplitude of about $\pm 1.4 \mathrm{~Sv}$ for the total length of PX30, with positive anomalies (northwestward across the section) in May-June and negative anomalies in October-November. The corresponding cycle from the model, sampled on the XBT line, has a maximum of $2.7 \mathrm{~Sv}$ in June and minimum of $-1.4 \mathrm{~Sv}$ in October; however the model includes a relatively strong semiannual component that is probably not resolved by the quarterly XBT sampling. The 1-cpy harmonic of model transport, which may be more comparable to the XBT value, has an amplitude of $\pm 1.7 \mathrm{~Sv}$ with its maximum in June, in good agreement with observations. When model transport on the XBT line is found top to bottom, the annual cycle amplitude is $\pm 4.4 \mathrm{~Sv}$, almost all of which occurs in the first harmonic. Unlike the situation in the warm layer above $12^{\circ} \mathrm{C}$, where significant annual variations occur nearly in phase all along the line, the annual cycle below $12^{\circ} \mathrm{C}$ is almost entirely in the western boundary layer.

No observations exist to describe the annual cycle of the NQC that would allow evaluation of the model depiction.

The longshore coherence of annual boundary transport anomalies seen in Fig. $3 \mathrm{~b}$ contrasts with the mean circulation, in which bifurcation of the SEC near $18^{\circ} \mathrm{S}$ divides water that flows northward into the equatorial current system from that which flows south along the coast of Australia (section 3). However, although the mean NQC feeds the NGCC directly (Fig. 1b), annual anomalies of the NQC shown here do not represent corresponding transports to the equator; indeed, the NQC is strong when the NGCC is weak, and vice versa. Instead, annual anomalies of boundary transport respond to changes of SEC inflow near $10^{\circ}-12^{\circ} \mathrm{S}$ : SEC strengthening in August-October feeds both equatorward anomalies of the NGCC and poleward anomalies of the NQC and EAC (Fig. 3b).

The annual longshore transport anomalies produce an annual shift in bifurcation latitude, which is farthest north in November-December when transport is anomalously southward. The shift amounts to about $\pm 1.25^{\circ}$ latitude in the vertical integral during the year, about the same magnitude as reported for the NEC bifurcation at the Philippines coast $(\mathrm{Qu}$ and Lukas 2003). However, this annual variability of the bifurcation point is a byproduct of variability of western boundary transport as a whole and does not in itself indicate changes in distribution of water masses into or 

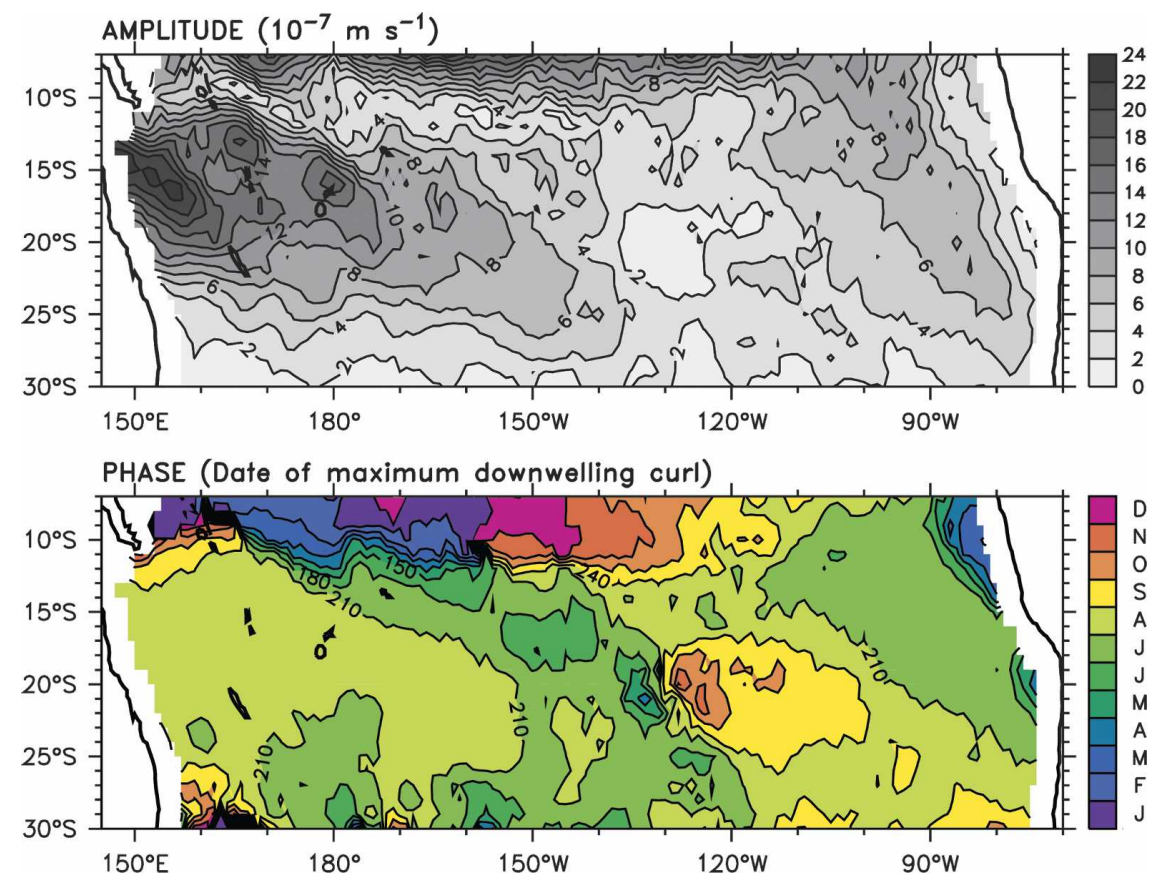

FIG. 4. The 1-cpy harmonic of the Ekman pumping velocity $\operatorname{Curl}[\tau /(f \rho)]$ from the ERS winds. (top) Amplitude $\left(10^{-7} \mathrm{~m} \mathrm{~s}^{-1}\right)$ and (bottom) phase [month of maximum negative (downwelling) curl].

out of the equatorial region. For example, a southward shift of the bifurcation might be thought to indicate more water flowing into the equatorial current system, as would be true for the mean. This appearance is misleading because annual northward transport anomalies along the coast of Australia do not feed the equator (Fig. 3b).

Similarly, the vertical coherence of the annual anomalies contrasts with the strong mean shear in the region of the bifurcation (section 3). Deep annual anomalies in the GBRUC region lag the surface by about 1 month, though the mean western boundary currents above and below the thermocline have opposite signs.

\section{c. Wind-driven dynamics of the annual cycle}

The variability described in section $4 \mathrm{~b}$ showed that annual fluctuations of western boundary transport along the coast of Australia occur nearly in phase from the tip of New Guinea at $10^{\circ} \mathrm{S}$ to $30^{\circ} \mathrm{S}$, with only a 2-month lag from north to south (Fig. 4b). This is surprising because neither of the two mechanisms that would be expected to control western boundary variability suggest such coherent signals: coastal Kelvin waves would travel from south to north, while midbasin wind forcing arriving as Rossby waves would be expected to show significant alongshore phase differences reflecting the strong meridional dependence of Rossby speed. Nevertheless, we argue here that these boundary current variations are consistent with the annual wind stress variability in the western South Pacific, acting principally through linear Rossby wave dynamics.

\section{1) THE INTERIOR}

The annual cycle of subtropical South Pacific wind stress curl has a simple pattern, with nearly uniform phase over the entire basin from $12^{\circ}$ to $30^{\circ} \mathrm{S}$, and amplitude dominated by strong variability in the Coral Sea, decaying eastward to very low values by $120^{\circ} \mathrm{W}$; a secondary, weaker, maximum occurs in the trade wind region near South America (Fig. 4). \{Note that Fig. 4 shows the Ekman pumping velocity $\operatorname{Curl}[\tau /(f \rho)]$ (where $\tau$ is the wind stress and $\rho$ is the density of seawater), which in these latitudes has a very similar pattern to that of $\operatorname{Curl}(\tau)$.\} Large amplitude of curl in the Coral Sea is consequent to annual north-south migration of west Pacific trades, which move with the sun more strongly and over a larger range of latitudes than those over the central and eastern South Pacific.

A sharp phase change and amplitude minimum stretches across the western and central basin at $10^{\circ}-$ $12^{\circ} \mathrm{S}$ (Fig. 4). Closer to the equator, the Ekman pumping velocity has a different character than its stationary oscillation in the subtropics. Instead, annual cycle 
winds in the equatorial band propagate westward at a speed of about $60 \mathrm{~cm} \mathrm{~s}^{-1}$, which has been shown to be a principal feature driving near-equatorial variability (Kessler and McCreary 1993; Wang et al. 2000; Chen and Qiu 2004).

As many others have done before (Meyers 1979; Kessler 1990; Chen and Qiu 2004), a first guess at the ocean response to this pattern of wind stress is made using a linear, reduced-gravity Rossby wave model:

$$
\frac{\partial h}{\partial t}+c_{r} \frac{\partial h}{\partial x}+R h=-\operatorname{Curl}\left(\frac{\tau}{f \rho}\right),
$$

where $h$ is the pycnocline depth anomaly (positive down). The long Rossby wave speed is $c_{r}=-\beta c^{2} / f^{2}$ ( $c$ is the internal long gravity wave speed, $f$ is the Coriolis parameter, and $\beta$ is its meridional derivative), and $R$ is a damping time scale. The two parameters to be chosen are $c$ and $R$, which we take, by experiment, to be $c=3.5 \mathrm{~m} \mathrm{~s}^{-1}$ and $R=(24 \text { months })^{-1}$. Results are not especially sensitive to either of these choices, primarily because the strongest forcing is in the far west (Fig. 4) so differences in propagation have little opportunity to manifest themselves. The model is forced with the annual cycle of ERS winds (Fig. 4); essentially the same winds used to force the OGCM. Ignoring the possibility of signals emanating from the eastern boundary (Kessler 1990; Minobe and Takeuchi 1995; Vega et al. 2003; Fu and Qiu 2002), the general solution to (1), obtained separately at each latitude, is

$$
\begin{aligned}
h(x, t)= & -\frac{1}{c_{r}} \int_{x_{E}}^{x} \exp \left[-\frac{R}{c_{r}}\left(x-x^{\prime}\right)\right] \\
& \times \operatorname{Curl}\left[\tau\left(x^{\prime}, t-\frac{x-x^{\prime}}{c_{r}}\right) / f \rho\right] d x^{\prime} .
\end{aligned}
$$

The lower limit of integration $x_{E}$ is the longitude of the eastern boundary, and because the integration is westward, $d x^{\prime}$ is negative. Note that $\operatorname{Curl}[\tau /(f \rho)]$ is evaluated not at solution time $t$ but at previous times looking back along the wave ray at speed $c_{r}$.

Chen and Qiu (2004) used a Rossby model similar to (1) to explain seasonal variability of the SECC, which flows above the thermocline roughly along $9^{\circ} \mathrm{S}$ east of the Solomon Island chain. They showed that for forcing of the simple form $\operatorname{Curl}[\tau /(f \rho)] \propto \exp \left[\left(x_{w}-x\right) / L\right]$ $\exp (i \omega t)$-namely, an oscillation with uniform phase that decays exponentially away from the western boundary $\left(x=x_{W}\right)$ with length scale $L$, solution (2) is a standing oscillation that lags the forcing by $\tan ^{-1}\left(\omega L / c_{r}\right)$ (assuming that the eastern boundary is sufficiently far away that the exponential can be taken to be zero there). This solution also has uniform phase in longitude and therefore does not appear to be propagating. As Chen and Qiu (2004) noted, annual wind stress curl variability in the subtropical South Pacific is, to first order, fairly well described by such a simple form, with uniform phase \{maximum downwelling $\operatorname{Curl}[\tau /(f \rho)]$ in August $\}$ and amplitude decaying eastward with a scale of about $9000 \mathrm{~km}$ (Fig. 4). For these parameters, the lag of the Chen and Qiu formulation varies from about $76^{\circ}$ at $10^{\circ} \mathrm{S}$ to $88^{\circ}$ at $30^{\circ} \mathrm{S}$, or 2.5 to 3 months. Thus we expect solution (2), forced with observed annual cycle winds (whose 1-cpy harmonic is shown in Fig. 4), to have nearly uniform phase over the western South Pacific (maximum $h$ in November) and amplitude growing to the west. This is in fact a reasonable description of the solution, for the region $25^{\circ} \mathrm{S}$ to about $12^{\circ} \mathrm{S}$, west of about $160^{\circ} \mathrm{W}$ (Fig. 5). North and east of a line arcing from New Guinea to $30^{\circ} \mathrm{S}, 90^{\circ} \mathrm{W}$, the Rossby solution depicts a classical crescent of wave crests propagating westward, but in the western South Pacific it is nearly stationary. South of $25^{\circ} \mathrm{S}$, where curl amplitude does not decay eastward (Fig. 4), the solution is again westward-propagating (Fig. 5). The 1-cpy harmonic of the depth of the $15^{\circ} \mathrm{C}$ isotherm in the full OGCM (Fig. 6) is remarkably similar to the simple Rossby solution (Fig. 5 ), in particular with respect to the large-amplitude, uniform-phase region in the west, a band of abrupt phase change and minimum amplitude stretching southeastward from New Guinea, and the regime change south of about $25^{\circ} \mathrm{S}$, indicating that these linear wind-forced dynamics dominate thermocline depth variability over the interior South Pacific. Roemmich and Cornuelle (1990) described a similar thermocline oscillation seen in the repeat XBT line along $180^{\circ}$.

The stationary Rossby solution for the Chen and Qiu (2004) form is similar to local Ekman pumping alone, which simply integrates over the annual cycle of forcing at each location, and lags the forcing by $90^{\circ}$. Because the Rossby integral is taken westward, it sums forcing that is increasing, so each phase more than cancels the previous one; the solution is therefore slightly ahead of the Ekman pumping result. As long as the distance traveled at Rossby speed $c_{r}$ in a year is comparable to or smaller than the exponential decay scale $L$, the difference between successive forcing phases is small, and the lag $\tan ^{-1}\left(\omega L / c_{r}\right)$ is only slightly less than $90^{\circ}$. Close to the equator, where $c_{r}$ grows, this interpretation becomes less tenable.

Morris et al. (1996) analyzed seven years of repeat, high-spatial-resolution XBT data along a line from Auckland to Fiji (roughly along the date line) and found that annual thermocline depth and zonal geostrophic current fluctuations lagged the wind stress curl forcing by 3 months, as well as could be measured given 

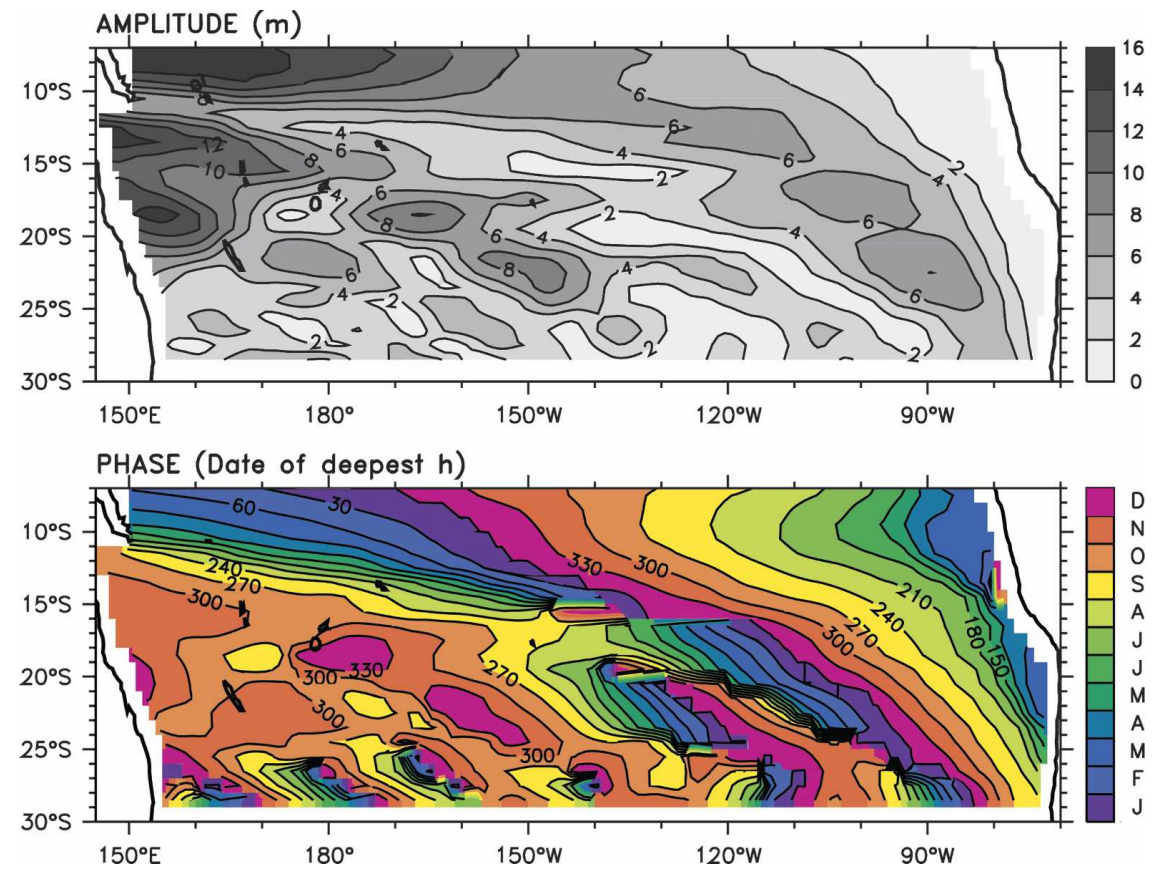

FIG. 5. The 1-cpy harmonic of Rossby model $h$. (top) Amplitude (m) and (bottom) phase (month of deepest $h$ ).

their roughly quarterly sampling. They concluded that this was consistent with local Ekman pumping, with no apparent influence of remote forcing. In hindsight, the roughly 3-month lag appears to be due to the particular shape of the annual South Pacific wind stress curl field, and does not indicate the absence of Rossby waves, which remain a good first-order representation of the physical situation.
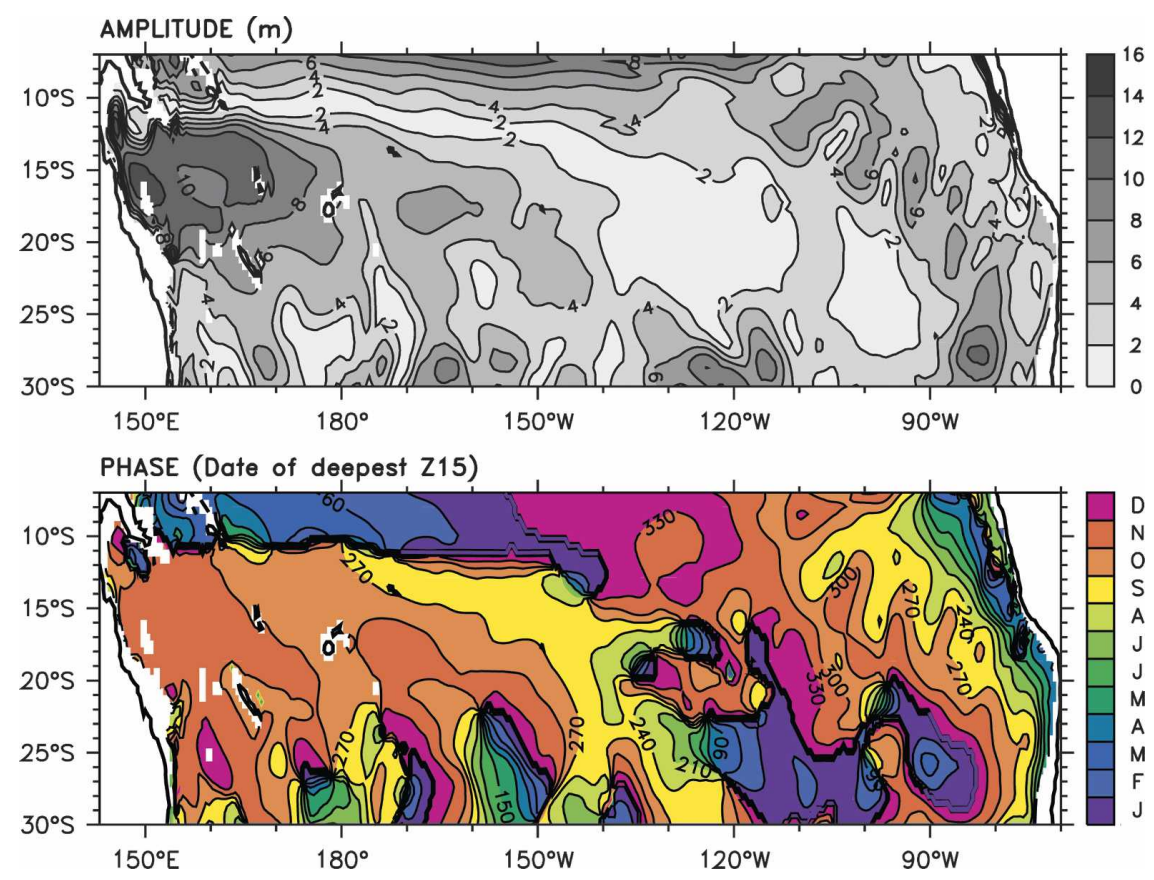

FIG. 6. The 1-cpy harmonic of $15^{\circ} \mathrm{C}$ depth from the OGCM. (top) Amplitude (m) and (bottom) phase (month of deepest isotherm depth). 
Since the Rossby model pycnocline solution in the southwest Pacific consists principally of a standing oscillation with largest amplitude in the Coral Sea (Fig. 5), the resulting geostrophic flow tendency is alternatively anticlockwise, strengthening the mean gyre circulation during the second half of the year (Fig. 3b), and clockwise during the first half. Two aspects modify this simple picture: First, the Coriolis parameter $f$ increases by a factor of about 2 between $10^{\circ}$ and $20^{\circ} \mathrm{S}$, so the tropical side has considerably stronger anomalies. Second, large-amplitude, nearly out-of-phase thermocline depth variability equatorward of $10^{\circ} \mathrm{S}$ (Fig. 5 from the Rossby model and Fig. 6 from the OGCM) is driven by equatorial winds and the Rossby waves they generate (Kessler and McCreary 1993; Wang et al. 2000; Chen and Qiu 2004). Thus, a strongly oscillating pressure gradient between the subtropics and the equatorial zone further amplifies annual zonal transport fluctuations along $10^{\circ} \mathrm{S}$, as also seen in the OGCM (Fig. 3b).

As noted in section 3 above (Fig. 2), the SEC inflow to the Coral Sea occurs primarily in two jets of roughly equal mean transport through the gap between New Caledonia and the Solomon Islands, with a total transport of about $30 \mathrm{~Sv}$. The annual cycle of thermocline depth demonstrated in the Rossby model solution suggests a variation of this transport of about $\pm 6 \mathrm{~Sv}$ during the course of the year, concentrated at the northern end, with maximum westward flow in November. This linear model prediction agrees fairly well in magnitude and spatial structure with the corresponding transport of the two jets from the OGCM and from CARS observations (Fig. 7). In all three estimates, almost all SEC transport variability occurs in the NVJ (and examination of transport as a function of latitude shows that even within the NVJ, annual variability is intensified to the north). Overall, the two model representations of the NVJ agree better with each other than with the CARS observations; since the models are forced with the same scatterometer winds for nearly the same period, while CARS includes observations over all time (in particular, it is based on many cruises along $165^{\circ} \mathrm{E}$ during the 1980s), it is not possible to determine if this reflects low-frequency changes or a failure of the models.

Although the NCJ at $15^{\circ}-20^{\circ} \mathrm{S}$ carries nearly half the mean transport into the Coral Sea, its annual variability is very small, less than one-third the NVJ signal in the observations, the OGCM, and the Rossby model (Fig. 7 , bottom). There is no correlation among the three estimates for this weak annual cycle of the $\mathrm{NCJ}$; the reason for this is not known. In contrast to the dominance of the NVJ in the annual cycle, interannual variability of the SEC in the OGCM during 1992-2001 is

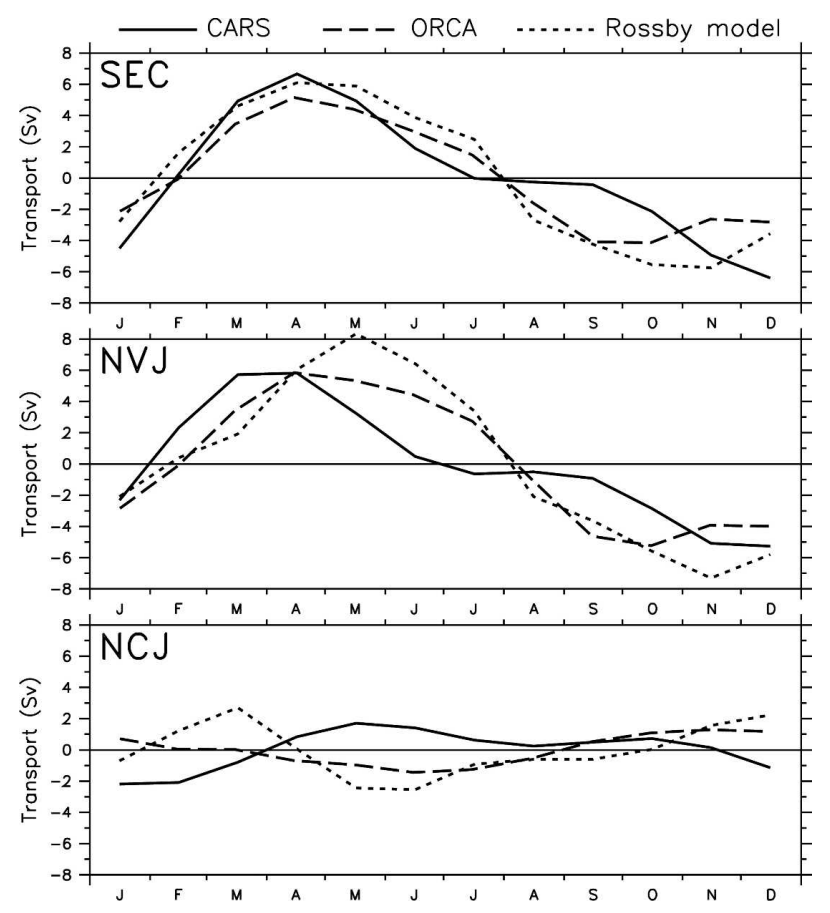

FIG. 7. Transport of the SEC, NVJ, and NCJ across $162^{\circ}-165^{\circ} \mathrm{E}$, from the CARS climatology (line), the OGCM (dashed), and the Rossby model (dotted). The NVJ is defined as flow between $15^{\circ}$ and $10^{\circ} \mathrm{S}$, and the NCJ between $20^{\circ}$ and $15^{\circ} \mathrm{S}$; the SEC is the sum of NVJ and NCJ (see Fig. 2). CARS is geostrophic and ORCA is total OGCM zonal current relative to $1000 \mathrm{~m}$.

about twice as large as the annual signal, and unlike the annual signal it is more evenly distributed across the two jets.

\section{2) THE Western BOUnDARY}

By its neglect of velocity acceleration terms, friction, and nonlinearity, the Rossby model (1) explicitly excludes western boundary dynamics, but the interior solution nevertheless has important implications for boundary current fluctuations. An estimate of the boundary transport can be made, relative to that at a poleward starting latitude $y_{S}$, by balancing the incoming zonal transport of the arriving Rossby waves (Godfrey 1975, see his appendix B.2). We assume that the Rossby transports are geostrophic, as is the longshore flow in the boundary layer, but the meridional momentum equation within the boundary layer may include lateral friction.

The Rossby height anomaly field at the offshore edge of the western boundary layer is $h_{\mathrm{RW}}$, given by (2) at its westernmost point. Since the boundary layer is thin, potential effects of the wind stress curl within it are ignored. The vertically integrated Rossby transport arriving at the boundary layer is 


$$
u_{\mathrm{RW}}=-\frac{g^{\prime} H}{f} \frac{\partial h_{\mathrm{RW}}}{\partial y}=-\frac{c^{2}}{f} \frac{\partial h_{\mathrm{RW}}}{\partial y},
$$

where the reduced gravity is $g^{\prime}$ and the mean upperlayer thickness is $H$. The gravity wave speed $c^{2}=g^{\prime} H$ has been previously chosen as a parameter of the Rossby model (1).

Starting at a latitude $y_{S}$, the incoming transport anomaly given by (3) is accumulated equatorward to find the boundary transport $V(y)$, integrated vertically and across the layer, relative to that at the poleward starting point $\left(V_{S}\right.$, at $\left.y_{S}\right)$ :

$$
V(y)-V_{S}=-\int_{y_{S}}^{y} u_{\mathrm{RW}} d y^{\prime}=\int_{y_{S}}^{y} \frac{c^{2}}{f} \frac{\partial h_{\mathrm{RW}}}{\partial y^{\prime}} d y^{\prime} .
$$

This may be integrated by parts to express the boundary transport, relative to that at $y_{S}$, in terms of the interior Rossby solution (2):

$V(y)=V_{S}+c^{2}\left[\frac{h_{\mathrm{RW}}(y)}{f}-\frac{h_{\mathrm{RW}}\left(y_{S}\right)}{f_{S}}+\int_{y_{S}}^{y} \frac{\beta}{f^{2}} h_{\mathrm{RW}} d y^{\prime}\right]$.

The value of $h$ at the coast can be found from (5), assuming that $V$ is geostrophic (Godfrey 1975).

Taking the boundary transports to be in steady balance with the interior solution assumes that the Kelvin wave, which is the transient response to the arriving Rossby wave, has passed the length of coast facing the interior ocean to its east; for the $2500 \mathrm{~km}$ of coast considered here that time scale is about 10 days, much shorter than the seasonal time scale of interest. On the other hand, the boundary transport $V_{S}$ at the poleward edge of the region is unknown because the Kelvin wave is assumed not to have passed completely around the continent of Australia-New Guinea. That time scale is likely to be very much longer than the simple transit time at speed $c$ because the continent extends just past the equator, so the Kelvin wave cannot simply continue around Australia but partially reflects into an equatorial Kelvin wave, propagates eastward to the American coast, and returns as Rossby waves. Thus the transport $V_{S}$ remains unknown, and only a solution relative to $y_{S}$ can be found.

This set of assumptions based on Godfrey (1975) differs from the "time-dependent island rule" of Firing et al. (1999), applicable to a small island (Hawaii) at low frequency. Firing et al. could assume that the adjustment of pressure around the island was completed in a time that is short relative to that of the incoming Rossby waves, which allowed them to construct a complete solution.

To use (5), we choose $y_{S}$ to be at $25^{\circ} \mathrm{S}$ for several reasons. The interior Rossby solution (2) has very small amplitude and ambiguous phase south of $25^{\circ} \mathrm{S}$, as compared with the robust result farther north (Fig. 5). This is inconsistent with the large observed annual amplitude of the EAC at these latitudes (Ridgway and Godfrey 1997), which is also reproduced in the OGCM here (Fig. 8, solid line). The EAC is known to become increasingly nonlinear south of about $26^{\circ} \mathrm{S}$, with energetic eddies that dominate the mean flow (Mata et al. 2000; Marchesiello and Middleton 2000; Ridgway 2006, manuscript submitted to Nature), finally separating from the coast between $28^{\circ}$ and $33^{\circ} \mathrm{S}$ (Godfrey et al. 1980; Boland and Church 1981). Thus it is unlikely that a linear representation will be useful at those latitudes. We therefore choose $y_{S}=25^{\circ} \mathrm{S}$ and use the OGCM transport there as $V_{S}$ in (5), yielding a Rossby estimate of the annual western boundary transport anomalies $V(y)$ (Fig. 8, dashed line). Since the Rossby model is linear, the various elements of wind forcing that produce this solution can also be isolated.

The Rossby estimate of the western boundary transport north of $25^{\circ} \mathrm{S}$ is similar in pattern to that of the OGCM, predicting a growth in amplitude up the coast, with a slight lead at $12^{\circ} \mathrm{S}$ relative to $25^{\circ} \mathrm{S}$, and then a sharp phase jump and amplitude minimum across $10^{\circ}-$ $11^{\circ} \mathrm{S}$ (Fig. 8). At the northernmost point along the coast of Australia that is exposed to the interior Pacific $\left(11.5^{\circ} \mathrm{S}\right)$, maximum southward anomalies occur in October; the maximum lags slowly to the south, to about 2 months later by $30^{\circ} \mathrm{S}$. This structure is also seen in Fig. $3 \mathrm{~b}$. The northward amplitude growth in the Rossby model is only about $70 \%$ of that in the OGCM, however, and the phase jump not quite as abrupt. This probably reflects the fact that that the Rossby model comprises a single baroclinic mode and thus does not encompass signals occurring below the thermocline; when only OGCM transport variability above $500 \mathrm{~m}$ is considered, its amplitude agrees closely with that of the Rossby model, and the $11^{\circ} \mathrm{S}$ phase shift appears more gradual.

North of $10.5^{\circ} \mathrm{S}$, along the coast of New Guinea, the phase of the OGCM boundary transport jumps, as inflow from the east splits to feed both southward flow along the coast of Australia and northward flow along the coast of New Guinea (e.g., Fig. 3b). The phase of the Rossby estimate (5) has a similar jump. Therefore, the phase shift in the full OGCM corresponds to the changing character of the linear, wind-driven Rossby solution, from propagating near the equator to stationary in the western subtropical gyre (Fig. 5). However, note that while the OGCM incorporates the existence of the continent and resulting western boundary dynamics, the Rossby solution does not; it is entirely due 


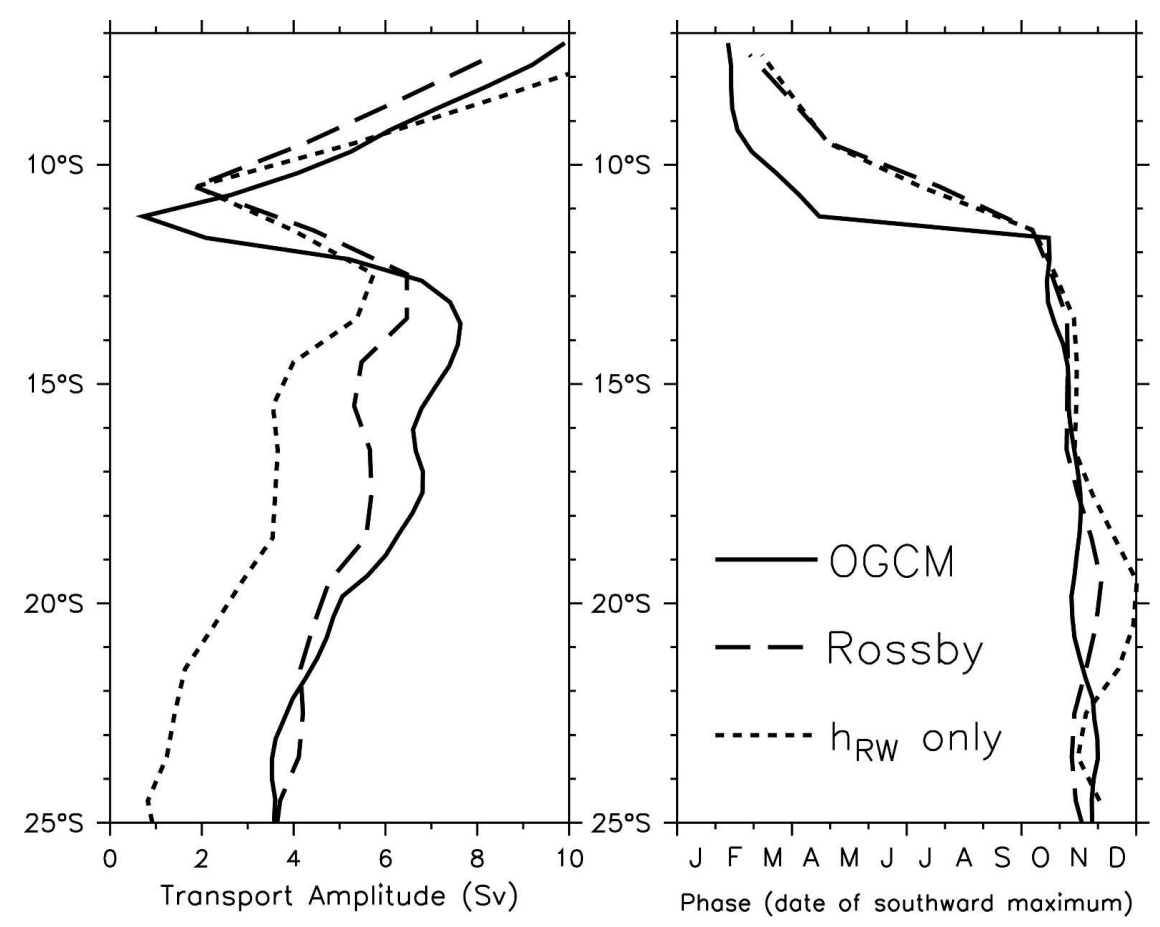

FIG. 8. The 1-cpy harmonic of western boundary current transport from the OGCM and the Rossby model. The legend for both panels is on the right. (left) Transport amplitude (Sv). (right) Phase (date of maximum southward transport). The solid line shows the transport in the OGCM, and the dashed line shows the solution from the Rossby model using (5), relative to the OGCM at $25^{\circ} \mathrm{S}$. The dotted line shows just the first term in the parentheses in (5), $c^{2} h_{\mathrm{RW}}(y) / f$, obtained from the zonally integrated wind stress curl at each latitude individually.

to the westward integral of wind stress curl, which changes phase abruptly across about $11^{\circ} \mathrm{S}$ (Fig. 4). This suggests that the abrupt phase shift of annual boundary current anomalies across $11^{\circ} \mathrm{S}$ is not due to the presence of the southeastern peninsula of New Guinea splitting the SEC, as might appear from Fig. 3b, but is driven by the shape of the wind forcing, in particular the sharp distinction between subtropical and equatorial winds (Wang et al. 2000; Chen and Qiu 2004).

The three terms in brackets on the right side of (5) have distinct physical interpretations. The first term $\left[c^{2} h_{\mathrm{RW}}(y) / f\right]$ is the geostrophic boundary current due directly to the interior Rossby signal arriving at each latitude, through the resulting coast-interior height difference. It contains the structure of the full Rossby solution as shown in Fig. 8, including the longshore coherence of the boundary currents along the Australian coast and sharp phase change at $11^{\circ} \mathrm{S}$, while the other terms are smaller modifications. The second term $\left[c^{2} h_{\mathrm{RW}}\left(y_{S}\right) / f_{S}\right]$, which is constant in latitude, is the poleward boundary condition in (4), canceling the first term at $y=y_{S}$ so (5) reduces to $V\left(y_{S}\right)=V_{S}$ there. The third (integral) term expresses the fact that an element of incoming Rossby height anomaly $h_{\mathrm{RW}}$ produces zonal geostrophic flows on its flanks that are not equal and opposite as they would be on an $f$-plane; instead, transport on the equatorward side of the $h_{\mathrm{RW}}$ element is larger because the magnitude of $f$ is smaller there. The imbalance is made up by an extra portion of boundary transport propagated equatorward of each element of $h_{\mathrm{RW}}$; this has opposite sign to that due to the coastinterior height difference, and therefore the $\beta$ contribution always reduces the direct effect of $h_{\mathrm{RW}}(y)$. In physical terms, this additional boundary flow not corresponding to $h_{\mathrm{RW}}(y)$ is associated with a longshore pressure gradient that balances boundary friction in the meridional momentum equation, which is not geostrophic in the boundary layer (Godfrey 1989). In the present case, the effect of $\beta$ is to reduce the magnitude of the boundary transport anomaly due to the first term by about $25 \%$, though the pattern of the variability is the same. The agreement between the Rossby model depiction and the full OGCM western boundary transports equatorward of $25^{\circ} \mathrm{S}$ (Fig. 8) shows that the boundary current anomalies principally depend on the interior forcing at each latitude individually [the first term, $\left.h_{\mathrm{RW}}(y)\right]$.

Additional experiments were conducted in which the 
Rossby model was forced only with winds in the eastern and western Pacific, respectively. These showed that annual western boundary current anomalies along the coast of Australia predicted by (5) are generated accurately by Coral Sea winds alone, with their large amplitude variations west of $165^{\circ} \mathrm{E}$ (Fig. 4), but variability along the coast of New Guinea that dominates the western boundary connection between the subtropics and the equator is driven by basin-scale near-equatorial winds.

\section{Summary and discussion}

Annual wind stress curl variations over the western South Pacific have a simple form (Fig. 4) that yields a simple solution based on linear Rossby dynamics [section 4c(1); Fig. 5]. The Rossby solution predicts that the subtropical thermocline of the western South Pacific should fluctuate with uniform phase from about $25^{\circ}$ to $10^{\circ} \mathrm{S}$, which is a good description of the variability seen in the full OGCM (Fig. 6), and is also in accord with XBT observations. While the classical arcs of westward-propagating Rossby crests are seen in the east, and also north of $10^{\circ} \mathrm{S}$ and south of $25^{\circ} \mathrm{S}$, the shape of annual variations of the wind (Fig. 4) generates a stationary, in-phase Rossby solution in the western subtropics (Fig. 5), which dominates in the full OGCM as well (Fig. 6). Thus, there is relatively little annual transport signal in the flat interior of the gyre, as flow anomalies occur principally around the edges of the in-phase region; the gyre alternately spins down in the first half of the year and up in the second.

Consistent with this picture of the interior thermocline and gyre, anomalous western boundary currents along the coast of Australia (the northward North Queensland Current and southward East Australian Current; Fig. 1b) fluctuate jointly: both are alternately northward and southward at the same times of year. The interior gyre spins up in September-October, increasing transport toward the coast at its northern end, and then the boundary current anomaly turns southward along the whole length of Australia in NovemberJanuary (Fig. 3b). The annual signal appears to propagate along the path of the flow anomaly maximum, from October east of the Solomon Islands, to arrive at the coast of north Queensland in November, and down the coast to $30^{\circ} \mathrm{S}$ in January (Fig. 3b).

The same SEC inflow that feeds the Australian coastal boundary currents also increases equatorward transport in the low-latitude western boundary currents, with a shorter lag. While the signal in the New Guinea Coastal Current is expected, the OGCM also develops a second oscillating equatorward boundary current along the east coast of the Solomon Islands (Fig. 3b) that has not been reported in the literature (though there are virtually no observations that would provide for its detection). This current does not occur in the mean and appears only below the thermocline in the OGCM; its realism is unknown.

The overview of annual boundary current anomalies in Fig. 3b is very different from the interpretation of the mean flow, in which bifurcation of the SEC near $18^{\circ} \mathrm{S}$ divides southward flow in the EAC that recirculates in the subtropical gyre, from northward flow in the NQC that feeds into the NGCC and reaches the equator (Tsuchiya 1981). This picture of the mean flow gives the impression that the bifurcation latitude is a key climate variable in determining the supply of water to the equatorial region and the subtropical-equatorial connection. (Indeed, that was our hypothesis in beginning this work.) However, we find that, for the annual cycle at least, when the SEC is strong it feeds water to the boundary such that both the NGCC is strong toward the equator and NQC/EAC anomalies are strong away from the equator. In an anomalous sense, then, there is no connection between the Australian western boundary currents or their bifurcation and the equatorial waveguide at the annual period.

This view raises a similar question about the bifurcation of the North Equatorial Current (NEC) along the coast of the Philippines, whose variability has also been interpreted as directing water toward or away from the equatorial current system ( $\mathrm{Qu}$ and Lukas 2003). The annual cycles of the Mindanao Current and Kuroshio at the Philippines show analogous behavior in being jointly northward or southward during the year (Qiu and Lukas 1996; Kim et al. 2004). While the NEC bifurcation is several degrees closer to the equator than that of the SEC, and the barrier of the narrow straits of the Solomon Sea does not exist in the north, it has not been shown that southward anomalies of the Philippine coastal boundary currents in boreal autumn influence the equator, or if they instead feed the North Equatorial Countercurrent, which is equally plausible. In general, the climatically relevant question of how the subtropical gyres connect to the equator requires close attention to the details of the low-latitude western boundary currents, which are not yet observed well enough to make these deductions with confidence.

Although the Rossby model studied here explicitly excludes western boundary dynamics, its interior solution has important implications for interpreting the boundary currents. A straightforward technique of estimating the western boundary transport as an equatorward accumulation of the zonal transport of incoming Rossby waves is appropriate for a wide range of inter- 
mediate frequencies (Godfrey 1975). This simple method represents the annual phase (and to a lesser extent the amplitude) of boundary currents along the whole length of coast from $25^{\circ}$ to $7^{\circ} \mathrm{S}$, including the northward-southward split of SEC inflow anomalies at $11^{\circ} \mathrm{S}$ (Fig. 8). Although the most realistic solution begins from a southern reference obtained from the OGCM, in fact the important details of the boundary currents can be estimated from the wind-driven Rossby solution integrated westward at each latitude individually.

Thus, much of the annual variability of the South Pacific subtropical gyre, even encompassing the western boundary currents from the central coast of Australia to the Solomon Sea, can be accounted for as a linear response to the nearly uniformly phased annual cycle of wind stress curl. It must be suspected, however, that the regions just north and south of this involve more complex dynamics. South of about $26^{\circ} \mathrm{S}$, nonlinearity becomes important in the East Australian Current and it separates from the coast (Godfrey et al. 1980), which influences the allocation of its transport among the shallow interior gyre (Ridgway and Dunn 2003), the Tasman front (Stanton et al. 1997), and to the south of Tasmania (Godfrey 1989; Speich et al. 2002; Cai 2006). North of the central Solomon Sea the distribution of western boundary transport among the three straits that open to the equator is almost completely unknown, yet this appears to have critical consequences for the structure of the equatorial current system and the impacts of the subtropics on it. Vitiaz Strait is only $40 \mathrm{~km}$ wide at the 500-m isobath, and St. Georges Channel is narrower than that, but about $20 \mathrm{~Sv}$ flows through them, with strong annual variability. Additional complexity is implied by the oscillating boundary current developed in the model along the east coast of the Solomon Islands (Fig. 3b) that feeds into the same regions. Clearly, modeling these narrow straits requires much higher resolution than is available in most global models (including the one studied here), but such a study would be academic because observations to check such a modeling exercise are unavailable. Lacking insight into how to attack these more difficult problems, we have chosen here to examine what appears to be the least complicated part of this system.

Acknowledgments. The authors thank their colleagues for thoughtful and perceptive suggestions while we took many twisting paths on the way to this paper: Alex Ganachaud, Greg Johnson, Christophe Maes, Jay McCreary, Bo Qiu, and, as always, the indispensable Dennis Moore. WSK is grateful to Ernest Frohlich and CSIRO for a sabbatical in Hobart that laid the founda- tion for this work and in particular for the chance to learn from Stuart Godfrey, the architect of many of these ideas. Raw material for this study was generously shared by its originators: the OGCM model output was provided by the OPA modeling team at LODYC, and the CARS CTD compilation was provided by Jeff Dunn and Ken Ridgway at CSIRO.

\section{REFERENCES}

Alory, G., and T. Delcroix, 2002: Interannual sea level changes and associated mass transports in the tropical Pacific from TOPEX/Poseidon data and linear model results (1964-1999). J. Geophys. Res., 107, 3153, doi:10.1029/2001JC001067.

Andrews, J. C., and S. Clegg, 1989: Coral Sea circulation and transport deduced from modal information models. Deep-Sea Res., 36A, 957-974.

Blanke, B., and S. Raynaud, 1997: Kinematics of the Pacific Equatorial Undercurrent: An Eulerian and Lagrangian approach from GCM results. J. Phys. Oceanogr., 27, 1038-1053.

— , S. Speich, G. Madec, and K. Döös, 2001: A global diagnostic of interocean mass transfers. J. Phys. Oceanogr., 31, 16231632.

Boland, F. M., and J. A. Church, 1981: The East Australian Current 1978. Deep-Sea Res., 28A, 937-957.

Bowen, M. M., J. L. Wilkin, and W. J. Emery, 2005: Variability and forcing of the East Australian Current. J. Geophys. Res., 110, C03019, doi:10.1029/2004JC002533.

Cai, W., 2006: Antarctic ozone depletion causes an intensification of the Southern Ocean super-gyre circulation. Geophys. Res. Lett., 33, L03712, doi:10.1029/2005GL024911.

Chen, S., and B. Qiu, 2004: Seasonal variability of the South Equatorial Countercurrent. J. Geophys. Res., 109, C08003, doi:10.1029/2003JC002243.

Church, J. A., 1987: East Australian Current adjacent to the Great Barrier Reef. Aust. J. Mar. Freshwater Res., 38, 671-683.

_ , and F. M. Boland, 1983: A permanent undercurrent adjacent to the Great Barrier Reef. J. Phys. Oceanogr., 13, 17471749.

Delcroix, T., G. Eldin, M. H. Radenac, J. M. Toole, and E. Firing, 1992: Variation of the western equatorial Pacific Ocean, 1986-1988. J. Geophys. Res., 97 (C4), 5423-5445.

DeSzoeke, R. A., 1987: On the wind-driven circulation of the South Pacific Ocean. J. Phys. Oceanogr., 17, 613-630.

Firing, E., B. Qiu, and W. Miao, 1999: Time-dependent Island Rule and its application to the time-varying North Hawaiian Ridge Current. J. Phys. Oceanogr., 29, 2671-2688.

$\mathrm{Fu}, \mathrm{L}$. L., and B. Qiu, 2002: Low-frequency variability of the North Pacific Ocean: The roles of boundary- and wind-driven baroclinic Rossby waves. J. Geophys. Res., 107, 3220, doi:10.1029/2001JC001131.

—, E. J. Christensen, C. A. Yamarone Jr., M. Lefebvre, Y. Ménard, M. Dorrer, and P. Escudier, 1994: TOPEX/ POSEIDON mission overview. J. Geophys. Res., 99, 24369 24381.

Fukumori, I., T. Lee, B. Cheng, and D. Menemenlis, 2004: The origin, pathway, and destination of Niño-3 water estimated by a simulated passive tracer and its adjoint. J. Phys. Oceanogr., 34, 582-604.

Galanti, E., and E. Tziperman, 2003: A midlatitudes-ENSO teleconnection mechanism via baroclinically unstable long Rossby waves. J. Phys. Oceanogr., 33, 1877-1888. 
Giese, B. S., S. C. Urizar, and N. Fuckar, 2002: Southern Hemisphere origins of the 1976 climate shift. Geophys. Res. Lett., 29, 1014, doi:10.1029/2001GL013268.

Godfrey, J. S., 1975: On ocean spindown I: A linear experiment. J. Phys. Oceanogr., 5, 399-409.

_ 1989: A Sverdrup model of the depth-integrated flow for the world ocean allowing for island circulations. Geophys. Astrophys. Fluid Dyn., 45, 89-112.

— , G. R. Cresswell, T. J. Golding, A. F. Pearce, and R. Boyd, 1980: The separation of the East Australian Current. J. Phys. Oceanogr., 10, 430-440.

Goodman, P. J., W. Hazeleger, P. de Vries, and M. Cane, 2005: Pathways into the equatorial undercurrent: A trajectory analysis. J. Phys. Oceanogr., 35, 2134-2151.

Gouriou, Y., and J. M. Toole, 1993: Mean circulation of the upper layers of the western equatorial Pacific Ocean. J. Geophys. Res., 98 (C12), 22 495-22 520.

Gu, D., and S. G. H. Philander, 1997: Interdecadal climate fluctuations that depend on exchanges between the Tropics and extratropics. Science, 275, 805-807.

Huang, R. X., and B. Qiu, 1998: The structure of the wind-driven circulation in the subtropical South Pacific Ocean. J. Phys. Oceanogr., 28, 1173-1183.

Izumo, T., J. Picaut, and B. Blanke, 2002: Tropical pathways, equatorial undercurrent variability and the 1998 La Niña. Geophys. Res. Lett., 29, 2080, doi:10.1029/2002GL015073.

Kalnay, E., and Coauthors, 1996: The NCEP/NCAR 40-Year Reanalysis Project. Bull. Amer. Meteor. Soc., 77, 437-471.

Kessler, W. S., 1990: Observation of long Rossby waves in the northern tropical Pacific Ocean. J. Geophys. Res., 95 (C4), 5183-5217.

—, and J. P. McCreary, 1993: The annual wind-driven Rossby wave in the subthermocline equatorial Pacific. J. Phys. Oceanogr., 23, 1192-1207.

— Pacific Ocean. Geophys. Res. Lett., 33, L03608, doi:10.1029/ 2005 GL025084.

Kim, Y. Y., T. Qu, T. Jensen, T. Miyama, H. Mitsudera, H.-W. Kang, and A. Ishida, 2004: Seasonal and interannual variations of the North Equatorial Current bifurcation in a high-resolution OGCM. J. Geophys. Res., 109, C03040, doi:10.1029/2003JC002013.

Kleeman, R., J. P. McCreary, and B. A. Klinger, 1999: A mechanism for generating ENSO decadal variability. Geophys. Res. Lett., 26, 1743-1746.

Levitus, S., and Coauthors, 1998: Introduction. Vol. 1, World Ocean Database 1998, NOAA Atlas NESDIS 18, 346 pp.

Lindstrom, E., R. Lukas, R. Fine, E. Firing, J. S. Godfrey, G. Meyers, and M. Tsuchiya, 1987: The western equatorial Pacific Ocean circulation study. Nature, 330, 533-537.

Luo, J.-J., S. Masson, S. Behara, P. Delecluse, S. Gualdi, A. Navarra, and T. Yamagata, 2003: South Pacific origin of the decadal ENSO-like variation as simulated by a coupled GCM. Geophys. Res. Lett., 30, 2250, doi:10.1029/2003GL018649.

Madec, G., P. Delecluse, M. Imbard, and C. Levy, 1998: OPA 8.1 Ocean General Circulation Model reference manual. Note du Pole de Modélisation, Institut Pierre-Simon Laplace, No. 11, $91 \mathrm{pp}$.

Marchesiello, P., and J. H. Middleton, 2000: Modeling the East Australian Current in the western Tasman Sea. J. Phys. Oceanogr., 30, 2956-2971.

Mata, M. M., M. Tomczak, S. Wijffels, and J. A. Church, 2000: East Australian Current volume transports at $30^{\circ} \mathrm{S}$ : Estimates from the World Ocean Circulation Experiment hydrographic sections PR11/P6 and the PCM3 current meter array. J. Geophys. Res., 105, 28 509-28 526.

Meyers, G., 1979: On the annual Rossby wave in the tropical North Pacific Ocean. J. Phys. Oceanogr., 9, 633-674.

Minobe, S., and K. Takeuchi, 1995: Annual period equatorial waves in the Pacific Ocean. J. Geophys. Res., 100 (C9), 18 379-18 392.

Morris, M., D. Roemmich, and B. Cornuelle, 1996: Observations of variability in the South Pacific subtropical gyre. J. Phys. Oceanogr., 26, 2359-2380.

Preisendorfer, R. W., 1988: Principal Component Analysis in Meteorology and Oceanography. Curtis Mobley, Ed., Elsevier, $425 \mathrm{pp}$.

Qiu, B., and R. Lukas, 1996: Seasonal and interannual variability of the North Equatorial Current, the Mindanao Current, and the Kuroshio along the Pacific western boundary. J. Geophys. Res., 101, 12 315-12 330.

, and S. Chen, 2004: Seasonal modulation of the eddy field of the South Pacific Ocean. J. Phys. Oceanogr., 34, 1515-1527.

Qu, T., and E. J. Lindstrom, 2002: A climatological interpretation of the circulation in the western South Pacific. J. Phys. Oceanogr., 32, 2492-2508.

- and R. Lukas, 2003: The bifurcation of the North Equatorial Current in the Pacific. J. Phys. Oceanogr., 33, 5-18.

Reid, J. L., 1986: On the total geostrophic circulation of the South Pacific Ocean: Flow patterns, tracers and transport. Progress in Oceanography, Vol. 16, Pergamon Press, 1-61.

Ridgway, K. R., and J. S. Godfrey, 1997: Seasonal cycle of the East Australian Current. J. Geophys. Res., 102, $22921-$ 22936.

_ , and J. R. Dunn, 2003: Mesoscale structure of the mean East Australian Current system and its relationship with topography. Progress in Oceanography, Vol. 56, Pergamon Press, 189-222.

__ _ _ _ and J. L. Wilkin, 2002: Ocean interpolation by weighted least squares-Application to the waters around Australia. J. Atmos. Oceanic Technol., 19, 1357-1375.

Roemmich, D., and B. Cornuelle, 1990: Observing the fluctuations of gyre-scale ocean circulation: A study of the subtropical South Pacific. J. Phys. Oceanogr., 20, 1919-1934.

_ J. Jilson, J. Willis, P. Sutton, and K. Ridgway, 2005: Closing the time-varying mass and heat budgets for large ocean areas: The Tasman Box. J. Climate, 18, 2330-2343.

Schlax, M. G., D. B. Chelton, and M. H. Freilich, 2001: Sampling errors in wind fields constructed from single and tandem scatterometer datasets. J. Atmos. Oceanic Technol., 18, 1014 1036.

Schneider, N., 2004: The response of the tropical climate to the equatorial emergence of spiciness anomalies. J. Climate, 17, 1083-1095.

_ A. J. Miller, M. A. Alexander, and C. Deser, 1999: The subduction of decadal North Pacific temperature anomalies: Observations and dynamics. J. Phys. Oceanogr., 29, 10561070.

Scully-Power, P. D., 1973: Coral Sea flow budget in winter. Aust. J. Mar. Freshwater Res., 24, 203-216.

Sokolov, S., and S. Rintoul, 2000: Circulation and water masses of the southwest Pacific: WOCE section P11, Papua New Guinea to Tasmania. J. Mar. Res., 58, 223-268.

Speich, S., B. Blanke, P. de Vries, S. Drijfhout, K. Doos, A. Ganachaud, and R. Marsh, 2002: Tasman leakage: A new route 
in the global conveyor belt. Geophys. Res. Lett., 29, 1416, doi:10.1029/2001GL014586.

Stanton, B., P. Sutton, and S. Chiswell, 1997: The East Auckland Current, 1994-95. N. Z. J. Mar. Freshwater Res., 31, 537-549.

—, D. Roemmich, and M. Kosro, 2001: A shallow zonal jet south of Fiji. J. Phys. Oceanogr., 31, 3127-3130.

Tsuchiya, M., 1981: The origin of the Pacific Equatorial $13^{\circ} \mathrm{C}$ water. J. Phys. Oceanogr., 11, 794-812.

- R. Lukas, R. A. Fine, E. Firing, and E. Lindstrom, 1989: Source waters of the Pacific Equatorial Undercurrent. Progress in Oceanography, Vol. 23, Pergamon Press, 101147.

Vega, A., Y. duPenhoat, B. Dewitte, and O. Pizarro, 2003: Equatorial forcing of interannual Rossby waves in the eastern
South Pacific. Geophys. Res. Lett., 30, 1197, doi:10.1029/ 2002GL015886.

Wang, B., R. Wu, and R. Lukas, 2000: Annual adjustment of the thermocline in the tropical Pacific Ocean. J. Climate, 13, 596616.

Webb, D. J., 2000: Evidence for shallow zonal jets in the South Equatorial Current region of the southwest Pacific. J. Phys. Oceanogr., 30, 706-720.

Wyrtki, K., 1962: Geopotential topographies and associated circulation in the western South Pacific Ocean. Aust. J. Mar. Freshwater Res., 13, 89-105.

Xie, P. P., and P. A. Arkin, 1997: Global precipitation: A 17-year monthly analysis based on gauge observations, satellite estimates, and numerical model outputs. Bull. Amer. Meteor. Soc., 78, 2539-2558. 